\section{Suppressed but still infectious}
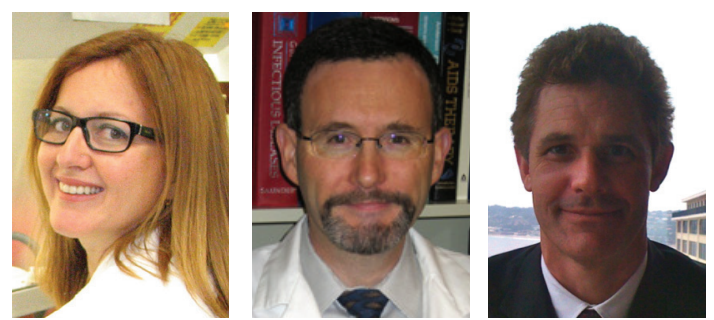

“... sexual HIV transmission

... can occur even in

treated individuals with

undetectable HIV RNA

levels in blood..."

Sara Gianella*1, Richard Haubrich' \& Sheldon R Morris ${ }^{1}$

University of California San Diego, 9500 Gilman Drive MC 0679, La Jolla, CA 92093-0679, USA

*Author for correspondence: Tel. . +1 8585528585 ext. 7193 = Fax: +1 8585527445 = gianella@ucsd.edu

The majority of HIV in the USA is transmitted through sexual intercourse. In 2011, diagnosed infections attributed to male-to-male sexual contact $(65 \%)$ and those attributed to heterosexual contact (27\%) accounted for approximately $92 \%$ of new HIV infections in the USA [101]. The current prevention paradigm suggests that early identification of HIV-infected individuals ('test') and early initiation of antiretroviral therapy (ART; 'treat') could lead to dramatic reductions in the incidence of HIV infection [1,2], and this 'test-and-treat' strategy for HIV prevention is supported by mathematical models and epidemiological data [2-4]. Additionally, data from a large randomized trial demonstrated a $92 \%$ reduction in HIV transmission within serodiscordant couples when the HIV-infected partner was placed on ART [3]. Nevertheless, incomplete engagement in HIV care is still common in the USA and the most recent estimate from the CDC is that only $66 \%$ of the 1.1 million Americans living with HIV are linked to care and only around one quarter have HIV RNA suppressed in plasma [102]. These incompletely engaged individuals continue to contribute to the ongoing transmission of HIV infection and pose substantial barriers to the achievement of optimal treatment outcomes. Additionally, high-risk individuals that understand the protective effect of ART on HIV transmission [5-7], and who are receiving ART (regardless of viral suppression) [8-10], have demonstrated increased risk behaviors - several studies have reported an increasing incidence of HIV among men who have sex with men (MSM), despite the widespread availability of ART [11-13]. Finally, sexual HIV transmission [14,15] and intermittent seminal HIV shedding [16] can occur even in treated individuals with undetectable HIV RNA levels in blood; it remains unclear how much of the residual risk of transmission is contributing to sustain the HIV epidemic at a population level.

Seminal HIV shedding during effective ART is intermittent, and the prevalence ranges from

$2 \%$ up to $48 \%$ (most studies have rates between 6 and 8\%) [17-23], depending on the characteristics of the observed population. Prevalence estimates increase when repeated longitudinal sampling is employed [17]. In addition, since most studies only measured cell-free HIV RNA in seminal plasma, the detectable rate of HIV in genital secretions may actually double if cellassociated HIV DNA and RNA transcripts are also measured [18].

\begin{abstract}
"Seminal HIV shedding during effective antiretroviral therapy is intermittent, and the prevalence ranges from $2 \%$ up to $48 \%$..."
\end{abstract}

These reported isolated seminal HIV shedding events in ART-treated individuals might be a consequence of viral compartmentalization [24] with poor drug penetration within the genital tract [16,25], or may arise from stimulation by concurrent sexually transmitted infections (STIs) and genital inflammation $[17,18,26-$ 28]. Our group has focused on identifying factors associated with HIV seminal shedding in asymptomatic MSM with and without ART [29-32]. In ART-naive MSM, we identified that seminal shedding of CMV, EBV and human herpes virus 8 were associated with increased HIV seminal shedding [29]; CMV and EBV were also associated with HIV transmission [30]. More recently, we reported that $6 \%$ of asymptomatic HIV-infected MSM on ART had detectable HIV RNA in semen, despite completely suppressed HIV RNA levels in blood, and the presence of bacterial STIs was not a major contributor to these viral shedding episodes [31]. In our study, the only independent predictor of seminal HIV RNA shedding was the concurrent detection of high-level CMV DNA in the genital tract. Another recent study on treated MSM with suppressed HIV RNA in the blood [23] observed a similar frequency of $7.6 \%$ seminal HIV shedding, which was

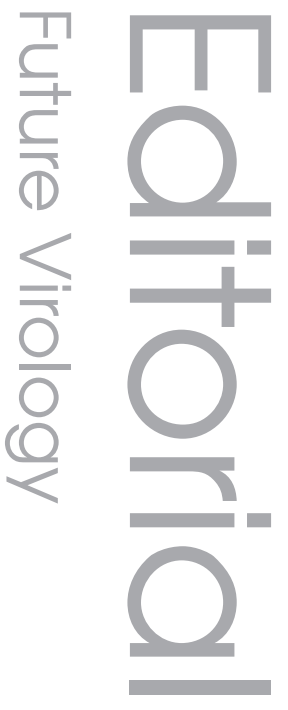

\section{Keywords}

- antiretroviral therapy - CMV coinfection = seminal

HIV shedding $=$ sexual HIV transmission = suppressed HIV RNA

\section{Future $\because$ Medicine part of}


associated with the size of the latent HIV reservoir in blood, but not with presence of STIs. The composition of the agents in the antiretroviral regimen has not generally been associated with differential shedding rates, with the exception of regimens containing raltegravir [31,33]. In our study, $4.8 \%$ of subjects on suppressive raltegravir regimens had seminal shedding compared with $9.9 \%$ on nonraltegravircontaining regimens, but this difference was not statistically significant [31].

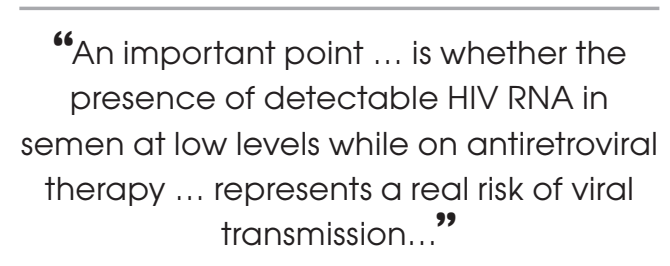

An important point, which remains to be determined, is whether the presence of detectable HIV RNA in semen at low levels while on ART (mostly found at levels $<1000$ copies/ $\mathrm{ml}$ ) represents a real risk of viral transmission during sexual intercourse. In addition, since the origin of transmitted virus (cell free vs cell associated) is still unresolved, the contribution of cell-associated HIV to sexual HIV transmission during suppressive ART needs to be studied further [34,35]. One study estimated heterosexual transmission using a probabilistic model for a seminal viral load of $<1000$ copies/ml to be $3 / 10,000$ sexual episodes [36], and this estimate is likely to be higher during anal intercourse. Another recent study described a stepwise association between levels of genital HIV RNA and HIV transmission risk among heterosexual couples [37], with a $1 \log _{10}$ increase in genital HIV RNA resulting in a $1.79-2.20$-fold increased risk of HIV transmission. In this study the risk of HIV transmission was estimated at 1.44.4 per 100 person-years when HIV RNA in genital secretion was $<3$ logs. Interestingly, a total of 11 transmissions (incidence $<1 \%$ per year) occurred from individuals with undetectable genital HIV RNA. However, all these subjects had detectable plasma HIV RNA levels, and the median time between collection of the genital sample from the source partner and HIV seroconversion was 4.6 months. Independently from HIV RNA levels in the genital tract, one study calculated a transmission rate of 0.37 (95\% CI: 0.09-2.04) per 100 person-years for ART-treated source partners, compared with 2.24 (95\% CI: 1.84-2.72) from ART-naive heterosexual partners, corresponding to a $92 \%$ reduction [3]. This is similar to a pooled estimate of transmission from heterosexuals on ART of 0.46 (95\% CI: 0.19-1.09) per 100 person-years [38].

Translating the individual estimates of HIV transmission risk into estimates of the overall effect of HIV spread among the growing number of ART-treated individuals is currently a challenge. We previously attempted to estimate the potential impact of HIV transmission in the USA related to MSM on ART with suppressed HIV RNA viral load [39], which gave a figure of approximately 3500 cases in 1 year. However, there are many factors that could significantly impact this estimate, and these should be accounted for. First, we used a probability of transmission of 0.00136 per act $(92 \%$ reduction from the estimate in untreated men of 0.017 [40]]). However, the true transmission per act during suppressive ART has not been well defined for MSM, and the $92 \%$ reduction applied to the empirically derived estimates of transmission with anal sex are higher than the mathematically modeled estimate of transmission with a seminal viral load <1000 copies/ml. Additionally, while it is relatively straight forward to estimate the number of ART-suppressed MSM living in the USA (as 25\% of the 489,121 HIV-infected MSM $[102,103])$, there is much less certainty regarding the number of unprotected anal sex acts per year these MSM are having with serodiscordant partnerships. Changes in risk behavior (i.e., risk compensation) may also be expected to increase with further dissemination of the belief in the protective effect of ART and use of pre-exposure prophylaxis [41].

\section{"...current scientific priorities should be concerned with HIV transmission from individuals on suppressive antiretroviral therapy..."}

Similar problems would exist when attempting to calculate the transmissions in heterosexual and injection drug users. Better accuracy and precision in the future will require a more definitive estimate of transmission probability and transmission risk behavior derived from empirical data. The point remains that with a growing number of individuals living with HIV and suppressed on ART, this group may still contribute substantially to the HIV epidemic.

In conclusion, there is accumulating evidence suggesting that HIV RNA can be detected in the semen of men, despite being on suppressive ART [17-23,31]. However, the clinical significance and contribution of the detected virus 
to ongoing HIV transmission remains unclear. One first step to investigate the clinical significance would be to determine the threshold of detectable seminal HIV RNA associated with culture-competent virus, but these studies would be confounded by the sensitivity of viral growth assays. There are very few observational data on transmission partner pairs where the sources are receiving ART and, although difficult, this research would greatly inform the topic. For example, some important open questions to be addressed would be: is there a threshold (and what is it) or a linear relationship for seminal viral load that is associated with HIV transmission, and how is this different for heterosexual and MSM sexual transmission? What is the origin of transmitted virus (cell free vs cell associated)? Given our recent observations on asymptomatic viral coinfections [31], especially CMV, could there be important cofactors that need further consideration? Interventional research should be performed to determine whether better genital tract-penetrating ART drugs or the suppression of CMV is effective in reducing HIV shedding in semen and eventually also impacting the risk of HIV transmission. Thus, current scientific priorities should be concerned with HIV transmission from individuals on suppressive ART and how such transmission can be prevented; this agenda will require a better understanding of the attributable proportion of HIV transmission that comes from treated HIVinfected subjects, and which factors contribute to enhancing the risk of HIV RNA shedding in semen during ART.

\section{Financial \& competing interests disclosure \\ This work was supported by the Department of Veterans Affairs, the James Pendleton Charitable Trust, amfAR grant no. 108537 with support from FAIR; NIH grant no. 7UM1AI068636-07; NIAID grant no. AI 064086 (K24 to R Haubrich), AI 069432 (UCSD ACTU) and AI 36214 (CFAR Clinical Investigation and Biostatistics Core); the California HIVIAIDS Res- earch Program (CHRP: MC08-SD-700 and EI-11-SD-005); and the Interdisciplicinary Research Fellowship in NeuroAIDS R25-MH081482. The funders had no role in study design, data collection and analysis, decision to publish, or preparation of the manuscript. $R$ Haubrich has received honoraria or consultant fees from BMS, Gilead Sciences and Janssen, and research support (to UCSD) from Abbott, GlaxoSmithKline, Pfizer and Merck. The authors have no other relevant affliations or financial involvement with any organization or entity with a financial interest in or financial conflict with the subject matter or materials discussed in the manuscript apart from those disclosed. \\ No writing assistance was utilized in the production of this manuscript.}

\section{References}

1. Dieffenbach CW, Fauci AS. Universal voluntary testing and treatment for prevention of HIV transmission. JAMA 301(22), 2380-2382 (2009).

2. Granich RM, Gilks CF, Dye C, De Cock KM, Williams BG. Universal voluntary HIV testing with immediate antiretroviral therapy as a strategy for elimination of HIV transmission: a mathematical model. Lancet 373(9657), 48-57 (2009).

3. Donnell D, Baeten JM, Kiarie J et al. Heterosexual HIV-1 transmission after initiation of antiretroviral therapy: a prospective cohort analysis. Lancet 375(9731), 2092-2098 (2010).

4. Das M, Chu PL, Santos GM et al. Decreases in community viral load are accompanied by reductions in new HIV infections in San Francisco. PLoS ONE 5(6), e11068 (2010).

5. Ostrow DE, Fox KJ, Chmiel JS et al. Attitudes towards highly active antiretroviral therapy are associated with sexual risk taking among HIV-infected and uninfected homosexual men. AIDS 16(5), 775-780 (2002).
6. Rawstorne P, Fogarty A, Crawford J et al. Differences between HIV-positive gay men who 'frequently', 'sometimes' or 'never' engage in unprotected anal intercourse with serononconcordant casual partners: positive health cohort, Australia. AIDS Care 19(4), 514-522 (2007).

7. Schwarcz S, Scheer S, Mcfarland W et al. Prevalence of HIV infection and predictors of high-transmission sexual risk behaviors among men who have sex with men. Am. J. Public Health 97(6), 1067-1075 (2007).

8. Dukers NH, Goudsmit J, De Wit JB, Prins M, Weverling GJ, Coutinho RA. Sexual risk behaviour relates to the virological and immunological improvements during highly active antiretroviral therapy in HIV-1 infection. AIDS 15(3), 369-378 (2001).

9. Hasse B, Ledergerber B, Hirschel B et al. Frequency and determinants of unprotected sex among HIV-infected persons: the Swiss HIV cohort study. Clin. Infect. Dis. 51(11), 1314-1322 (2010).

10. Ostrow DG, Silverberg MJ, Cook RL et al. Prospective study of attitudinal and relationship predictors of sexual risk in the multicenter AIDS cohort study. AIDS Behav. 12(1), 127-138 (2008).

11. Katz MH, Schwarcz SK, Kellogg TA et al. Impact of highly active antiretroviral treatment on HIV seroincidence among men who have sex with men: San Francisco. Am. J. Public Health 92(3), 388-394 (2002).

12. Prejean J, Song R, Hernandez A et al. Estimated HIV incidence in the United States, 2006-2009. PLoS ONE 6(8), e17502 (2011).

13. Finlayson TJ, Le B, Smith A et al. HIV risk, prevention, and testing behaviors among men who have sex with men - National HIV Behavioral Surveillance System, 21 U.S. cities, United States, 2008. MMWR Surveill. Summ. 60(14), 1-34 (2011).

14. Lu W, Zeng G, Luo J et al. HIV transmission risk among serodiscordant couples: a retrospective study of former plasma donors in Henan, China. J. Acquir. Immune Defic. Syndr. 55(2), 232-238 (2010).

15. Sturmer M, Doerr HW, Berger A, Gute P. Is transmission of HIV-1 in non-viraemic serodiscordant couples possible? Antivir. Ther. 13(5), 729-732 (2008). 
16. Taylor S, Davies S. Antiretroviral drug concentrations in the male and female genital tract: implications for the sexual transmission of HIV. Curr. Opin. HIV AIDS 5(4), 335-343 (2010).

17. Sheth PM, Yi TJ, Kovacs C et al. Mucosal correlates of isolated HIV semen shedding during effective antiretroviral therapy. Mucosal Immunol. 5(3), 248-257 (2012).

18. Politch JA, Mayer KH, Welles SL et al. Highly active antiretroviral therapy does not completely suppress HIV in semen of sexually active HIV-infected men who have sex with men. AIDS 26(12), 1535-1543 (2012).

19. Halfon P, Giorgetti C, Khiri H et al. Semen may harbor HIV despite effective HAART: another piece in the puzzle. PLoS ONE 5(5), e10569 (2010).

20. Marcelin AG, Tubiana R, Lambert-Niclot $S$ et al. Detection of HIV-1 RNA in seminal plasma samples from treated patients with undetectable HIV-1 RNA in blood plasma. AIDS 22(13), 1677-1679 (2008).

21. Lorello G, La Porte C, Pilon R, Zhang G, Karnauchow T, Macpherson P. Discordance in HIV-1 viral loads and antiretroviral drug concentrations comparing semen and blood plasma. HIV Med. 10(9), 548-554 (2009).

22. Lambert-Niclot $S$, Tubiana R, Beaudoux $\mathrm{C}$ et al. Detection of HIV-1 RNA in seminal plasma samples from treated patients with undetectable HIV-1 RNA in blood plasma on a 2002-2011 survey. AIDS 26(8), 971-975 (2012).

23. Ghosn J, Delobelle A, Leruez-Ville M et al. HIV shedding in semen of men who have sex with men on efficient cART is associated with high HIV-DNA levels in PBMC but not with residual HIV-RNA viremia. Presented at: IAS 7th Conference on HIV Pathogenesis, Treatment and Prevention. Kuala Lumpur, Malaysia, 30 June-3 July 2013.

24. Craigo JK, Gupta P. HIV-1 in genital compartments: vexing viral reservoirs. Curr. Opin. HIV AIDS 1(2), 97-102 (2006).

25. Else LJ, Taylor S, Back DJ, Khoo SH. Pharmacokinetics of antiretroviral drugs in anatomical sanctuary sites: the male and female genital tract. Antivir. Ther. 16(8), 1149-1167 (2011).

26. Sheth PM, Kovacs C, Kemal KS et al. Persistent HIV RNA shedding in semen despite effective antiretroviral therapy. AIDS 23(15), 2050-2054 (2009).

27. Anderson JA, Ping LH, Dibben O et al. HIV-1 Populations in semen arise through multiple mechanisms. PLoS Pathog. 6(8), e1001053 (2010).

28. Cohen MS. Sexually transmitted diseases enhance HIV transmission: no longer a hypothesis. Lancet 351(Suppl. 3), 5-7 (1998).

29. Gianella S, Morris SR, Anderson C et al. Herpesviruses and HIV-1 drug resistance mutations influence the virologic and immunologic milieu of the male genital tract. AIDS 27(1), 39-47 (2013).

30. Gianella S, Morris SR, Vargas MV et al. The role of seminal shedding of herpesviruses in HIV-1 transmission. J. Infect. Dis. 207(2), 257-261 (2012).

31. Gianella S, Smith DM, Vargas MV et al. Shedding of HIV and human herpesviruses in the semen of effectively treated HIV-1infected men who have sex with men. Clin. Infect. Dis. 57(3), 441-447 (2013).

32. Gianella S, Strain MC, Rought SE et al. Associations between virologic and immunologic dynamics in blood and in the male genital tract. J. Virol. 86(3), 1307-1315 (2012).

33. Osborne BJ, Sheth PM, Yi TJ et al. Impact of antiretroviral therapy duration and intensification on isolated shedding of HIV-1 RNA in semen. J. Infect. Dis. 207(8), 1226-1234 (2013).

34. Butler DM, Delport W, Kosakovsky Pond SL et al. The origins of sexually transmitted HIV among men who have sex with men. Sci. Transl. Med. 2(18), 18re11 (2010).

35. Anderson DJ, Politch JA, Nadolski AM, Blaskewicz CD, Pudney J, Mayer KH. Targeting Trojan horse leukocytes for HIV prevention. AIDS 24(2), 163-187 (2010).
36. Chakraborty H, Sen PK, Helms RW et al. Viral burden in genital secretions determines male-to-female sexual transmission of HIV-1: a probabilistic empiric model. AIDS 15(5), 621 (2001).

37. Baeten JM, Kahle E, Lingappa JR et al. Genital HIV-1 RNA predicts risk of heterosexual HIV-1 transmission. Sci. Transl. Med. 3(77), 77ra29 (2011).

38. Attia S, Egger M, Muller M, Zwahlen M, Low N. Sexual transmission of HIV according to viral load and antiretroviral therapy: systematic review and meta-analysis. AIDS 23(11), 1397-1404 (2009).

39. Morris SR, Smith DM, Little SJ, Gianella S. Reply to Mounzer and DiNubile. J. Infect. Dis. 208(4), 711-712 (2013).

40. Boily MC, Baggaley RF, Wang L et al. Heterosexual risk of HIV-1 infection per sexual act: systematic review and metaanalysis of observational studies. Lancet Infect. Dis. 9(2), 118-129 (2009).

41. Eaton LA, Kalichman S. Risk compensation in HIV prevention: implications for vaccines, microbicides, and other biomedical HIV prevention technologies. Curr. HIVIAIDS Rep. 4(4), 165-172 (2007).

\section{Websites}

101. CDC. HIV surveillance report, vol. 23 (2011). www.cdc.gov/hiv/library/reports/ surveillance/index.html (Accessed 15 August 2013)

102. CDC. HIV surveillance report. www.cdc.gov/nchhstp/newsroom/docs/2012/ stages-of-carefactsheet-508.pdf (Accessed 15 August 2013)

103. CDC. Estimated HIV incidence among adults and adolescents in the United States, 2007-2010. HIV surveillance report, vol. 23 (2011). www.cdc.gov/hiv/risk/gender/msm/facts/ index.html (Accessed 15 August 2013) 